\title{
Práticas Integrativas para Melhoria da Qualidade de Vida no Trabalho em uma Farmácia Hospitalar
}

\author{
Castanheira, Maria de Fátima; Takeda, Osvaldo Hakio; Nascim, Maria Helena F. do; Kole, \\ Monika; Yui, Cristina; Sant, Renato Del; Martins, Marcelo Girotto; \\ Instituto de Psiquiatria do Hospital das Clínicas da Faculdade de Medicina da Univesidade de São Paulo - \\ m.castanheira@hc.fm.usp.br
}

Introdução: em 1990, os distúrbios neuropsiquiátricos respondiam por $10,5 \%$ dessas incapacidades e estavam entre as 20 principais causas no cálculo dos anos de vida perdidos ajustados por incapacidade (AVAI). Além dos altos custos para os sistemas de saúde e para as famílias, a assistência em saúde mental gera um ônus de pouca visibilidade: a sobrecarga imposta aos profissionais responsáveis. Estudos internacionais mostram que o trabalho em saúde mental é potencialmente um fator de estresse e esgotamento, podendo afetar a qualidade da assistência e, em casos extremos, inviabilizar a continuidade de serviços. o impacto destes índices é apontado por Cadilhe et al. (1994), ao reconhecer os transtornos mentais como as doenças que afastam por mais tempo as pessoas do trabalho. para propiciar sensação de maior harmonia e bem estar no ambiente de trabalho é utilizada a aplicação de terapias milenares de origem oriental, e outras desenvolvidas a partir do século passado que atuam no equilíbrio entre o corpo e a mente, em ambiente acolhedor e especialmente preparado, tais como: Reiki: método de cura natural pelas mãos para promover o completo equilíbrio energético, prevenção das disfunções e para possibilitar as condições necessárias a um completo bem estar; Shiatsu: terapia corporal pelo toque manual ou digital sobre a pele com o objetivo de tratar ou prevenir doenças pela estimulação dos mecanismos de recuperação naturais do corpo, fortalecer o sistema imunológico, melhorando a saúde física e emocional; e TISE® (Toque Integrativo Somato Emocional): terapêutica manual e corporal de facilitação do equilíbrio estrutural, da conscientização e manejo das experiências traumáticas em favor da integração mente-corpo, desbloqueia estruturas físicas de contenção do estresse emocional, liberando o fluxo circulatório. Objetivo: Avaliar se apenas com uma aplicação de práticas integrativas é possível obter maior harmonia e bem estar no ambiente de trabalho. Método: Aplicação de uma seção de Shiatsu, TISE ou Reiki para cada um dos funcionários da farmácia de um hospital neuropsiquiátrico de alta complexidade. Resultados: Houve aderência de $82 \%$ (18) dos funcionários, sendo que apenas $4 \%$ (1) dos funcionários não quis participar. a percepção individual de melhora logo após a aplicação foi em 56\% (10) dos funcionários, sendo que em 44\% (8) foi surpreendente. a percepção individual depois de 7 dias: 89\% (16) funcionários ainda se sentiam melhor. Conclusão: Apesar de cada funcionário ter recebido apenas uma sessão foi observado maior harmonização e bem estar no ambiente de trabalho, refletindo na qualidade individual e coletiva.

Castanheira, Maria de Fátima; Takeda, Osvaldo Hakio; Nascim, Maria Helena F. do; Kole, Monika; Yui, Cristina; Sant, Renato Del; Martins, Marcelo Girotto;. Práticas Integrativas para Melhoria da Qualidade de Vida no Trabalho em uma Farmácia Hospitalar. In: Anais do Congresso Internacional de Humanidades \& Humanização em Saúde [= Blucher Medical Proceedings, num.2, vol.1]. São Paulo: Editora Blucher, 2014. ISSN 2357-7282

DOI 10.5151/medpro-cihhs-10584 